\title{
In Vitro Steroidogenesis in Testes of Three Infants, Two with Ambiguous External Genitalia and One with True Precocious Puberty: Evidence for the Presence of Active $17 \beta$-Hydroxysteroid Oxidoreductase in Immature Human Testes
}

\author{
Hiroyuki OSHIMA ${ }^{1}$, DAISUKe ISHIWATA ${ }^{1}$, Shigeru HATAKEYAMA ${ }^{2}$ \\ AND MASAYUKI YOKOKAWA ${ }^{1}$ \\ ${ }^{1}$ Department of Urology and ${ }^{2}$ Department of Pathology, Tokyo Medical \\ and Dental University School of Medicine, Tokyo 113, Japan
}

\begin{abstract}
Synopsis
The present report investigated steroidogenesis in vitro in testis tissues obtained from two boys aged 8 months and 4 years with ambiguous external genitalia and male vagina, and a 4-year-old boy with true precocious puberty. Histologically, testes of the former two boys are still immature and the testis of the last one contains differentiated Sertoli cells and primary spermatocytes, but no mature Leydig cells are recognized in any of them. In each testis, $17 \beta$-hydroxysteroid oxidoreductase is active for androstenedione in the presence of an excess amount of NADPH, while $\Delta^{5}$. $3 \beta$-hydroxysteroid dehydrogenase and $\Delta^{4}$-steroid $5 \alpha$-reductase activities are limited. $17 \alpha$-Hydroxylase and C17-20 lyase are significantly active in each testis and are enhanced in the testis of the boy with precocious puberty. Although the testis tissue used in the present study may not be biologically normal and the number of cases investigated is still limited, the above results indicate that active $17 \beta$-hydroxysteroid oxidoreductase is present in immature human testes and that $\Delta^{5}-3 \beta$-hydroxysteroid dehydrogenase may become active in the human testis at the advanced stage of the development of testicular function during the puberty.
\end{abstract}

In human males, plasma testosterone falls to the baseline prepubertal levels of $5 \mathrm{ng} / \mathrm{d} l$ by about 6 months after delivery (Forest et al., 1976). In puberty an adult pattern of testicular functions becomes established, resulting in manifestation of male secondary sexual characteristics. The change of testicular steroidogenesis during the puberty is based on the enhanced activity of enzymes related to testosterone biosynthesis. Studies of in vitro steroidogenesis in prepubertal and pubertal testes of the human have been very limited (Oshima, 1971; Richards and Neville, 1973 ; Payne and Jaffe, 1975 ; Mizu-

Received May 26, 1979.

Mailing address : Dr. Hiroyuki Oshima, Department of Urology, Tokyo Medical and Dental University School of Medicine, 1-5-45 Yushima, Bunkyo-ku, Tokyo 113, Japan. tani et al., 1977), while the pattern of the induction of these enzyme activities during puberty in the human testis still remains unknown.

The major aim of the present paper is to offer informations to suggest the answer for the above problem by studying in vitro steroidogenesis in immature human testes.

Trivial names and abbreviations used in this text are as follows: pregnenolone, $3 \beta$-hydroxypregn-5-en20-one; $17 \alpha$-hydroxypregnenolone, $3 \beta, 17 \alpha$-dihydroxypregn-5-en-20-one; dehydroepiandrosterone, $3 \beta$-hydroxyandrost-5-en-17-one ; 5-androstenediol, androst5-ene-3 $\beta, 17 \beta$-diol; progesterone, pregn-4-ene-3, 20dione ; $17 \alpha$-hydroxyprogesterone, $17 \alpha$-hydroxypregn4-ene-3, 20-dione; androstenedione, androst-4-ene-3, 20 -dione; testosterone, $17 \beta$-hydroxyandrost-4-en-3one ; $20 \alpha$-dihydroprogesterone, $20 \alpha$-hydroxypregn-4en-3-one; $16 \alpha$-hydroxyprogesterone, 16 $\alpha$-hydroxypregn-4-ene-3, 20-dione; LH, luteinizing hormone; FSH, follicle stimulating hormone; and hCG, human chorionic gonadotropin. 


\section{Materials and Methods}

\section{Patients}

The clinical profile of patients studied in the present report is indicated in Table 1. Laparotomy of R. G. and Y. H. revealed neither uterus nor Fallopian tubes. Their abdominal testes were removed and used for the present in vitro study. T. T. with true precocious puberty manifested sexual maturation of Tanner II grade (Tanner, 1962). Clinical examinations and clinical course for more than 4 years revealed no signs of intracranial tumors nor any other endocrine disorders. When his testis was obtained by biopsy at 4 years old, no radioimmunoassay was available for gonadotropins and testosterone, and his urinary excretion of FSH and LH was determined by bioassay as approximately $210 \mu \mathrm{g}$ (equivalent to NIH-FSH-S S $_{3}$ /day (Steelman and Pohley, 1954; normal range, $253-393 \mu \mathrm{g} /$ day, $\mathrm{n}=8$ ) and $50 \mu \mathrm{g}$ (equivalent to NIH-LH-S $196551-107 \mu \mathrm{g} /$ day, $\mathrm{n}=8$ ), respectively.

\section{Tissue preparation and incubation}

Immediately after the removal, a part of the testis tissue was reserved for morphological examination, which was fixed with either Bouin's solution or double fixatives of $2 \%$ gluta-raldehyde in $0.1 \mathrm{M}$ phosphate buffer $(\mathrm{pH} 7.4)$ and then $1 \% \mathrm{OsO}_{4}$ in the same buffer. The remained tissue was decapsulated on ice, weighed and rinsed with ice-cold $0.25 \mathrm{M}$ sucrose solution ( $\mathrm{pH}$ 7.4). The cell-free homogenate was prepared as previouly described (Oshima et al., 1974) and incubated with one of steroid substrates containing $10 \times 10^{4} \mathrm{dpm}$ of corresponding $4-{ }^{14} \mathrm{C}$-labeled steroid preparation as indicated in Table 2. Cofactors used were $0.24 \mathrm{~mm}$ NAD and $0.12 \mathrm{~mm}$ NADPH for the incubation of pregnenolone and $0.12 \mathrm{mM} \mathrm{NADPH}$ for other steroid substrates. The final incubation medium was adjusted to the volume of $5 \mathrm{ml}$ and contained one of steroid substrates, required cofactor(s), $0.25 \mathrm{M}$ sucrose, $10 \mathrm{mM}$ Tris ( $\mathrm{pH} 7.4$ ), $1 \mathrm{mM}$ $\mathrm{MgCl}_{2}$ and the cell-free homogenate. Enzyme reactions were started by adding the tissue preparation and carried out at $37^{\circ} \mathrm{C}$ for $20 \mathrm{~min}$ by constant shaking under a gas phase of $95 \% \mathrm{O}_{2}$ and $5 \% \mathrm{CO}_{2}$, and then terminated by adding $10 \mathrm{~m} l$ of methylenedichloride followed by the vigorous shake of the incubation flask. The organic solvent phase was separated and dried over anhydrous sodium sulfate. The extraction of steroids was repeated two more times in the same manner after adding non-radioactive carrier steroids. More than $95 \%$ of the radioactivity initially added was recovered in the combined extracts.
Table 1. Clinical profile of patients

\begin{tabular}{llll}
\hline \multicolumn{1}{c}{ Patient } & \multicolumn{1}{c}{ R. G. } & Y. H. & \multicolumn{1}{c}{ T. T. } \\
\hline Age & 8 month & 4 years & 4 years \\
Sex assignment & female & female male \\
Chromosome & $46, \mathrm{XY}$ & $46, \mathrm{XY}$ & $46, \mathrm{XY}$ \\
Clinical & Hypospadia with & Idiopathic \\
conditions & vagina, abdominal true preco- \\
& and inguinal testes cious puberty \\
Testis tissue & Removed abdominal & Biopsy \\
used for study & testis \\
Testis size & $1.2 \mathrm{~g}(.87 \mathrm{~g} *)$ & $0.8 \mathrm{~g}(.44 \mathrm{~g}) 15 \mathrm{~m} l^{* *}$ \\
\hline * Weight of & whole removed testis (weight after \\
decapsulation). & $* *$ Measured with orchidometer.
\end{tabular}

Table 2. Amount of steroid substrate and tissue preparations used for incubation studies

\begin{tabular}{lccc}
\hline & R. G. & Y. H. & T. T. \\
\hline Substrate (nmoles/flask) & & & \\
$\quad$ Pregnenolone & 31.6 & 15.8 & 15.8 \\
Progesterone & 31.8 & 15.9 & 15.9 \\
$\quad$ 17 $\alpha$-Hydroxyprogesterone & - & 15.1 & 15.1 \\
Androstenedione & 34.9 & 17.5 & 17.5 \\
\hline Cell-free homogenate (mg/flask) & & \\
$\quad$ Equivalent wet tissue & 260 & 100 & 1000 \\
Protein & 19.2 & 7.8 & 44 \\
\hline
\end{tabular}

\section{Isolation and identification of metabolites}

An aliquot of each extract was applied to the ascending chromatography of a thin-layer plate prepared with $4: 1(\mathrm{w} / \mathrm{w})$ a mixture of silica gel $G$ and $\mathrm{GF}_{254}$ (E. Merck, AG. Darmstadt, Germany), which was developed in the solvent system of benzene and acetone $(4: 1, \mathrm{v} / \mathrm{v})$. Carrier steroids not distinctly separated by this initial solvent system were subjected to further separation by thin-layer chromatography using solvent systems previously described (Oshima et al., 1974).

Radioactive $17 \alpha$-hydroxypregnenolone, dehydroepiandrosterone and 5-androstenediol produced from pregnenolone by the testis tissue obtained from $T$. T. were acetylated with a mixture of pyridine and acetic anhydride $(1: 1 . \mathrm{v} / \mathrm{v})$ and then recrystallized to constant specific radioactivities with non-radioactive authentic preparations. $20 \alpha$-Dihydroprogesterone produced from progesterone and testosterone produced from either androstenedione or $17 \alpha$-hydroxyprogesterone in the tissue preparation of $\mathrm{T}$. T. were also recrystallized to constant specific radioactivities with corresponding authentic steroid preparations. Other radioactive metabolites produced by the testis of $T$. $T$. and all metabolites produced by the incubation of testis tissues of either R. G. or Y. H. under similar 
Table 3. Metabolism of pregnenolone by infantile testes

\begin{tabular}{lccr}
\hline & R. G. & Y. H. & T. T. \\
\hline Pregnenolone (substrate) & $70.5^{*}$ & 89.6 & 38.2 \\
$17 \alpha$-Hydroxypregnenolone & 5.7 & 2.6 & 11.3 \\
Dehydroepiandrosterone & 1.0 & 2.6 & 4.9 \\
5-Androstenediol & 3.0 & 0.5 & 4.9 \\
Progesterone & 1.0 & 0.5 & 1.0 \\
17 $\alpha$-Hydroxyprogesterone & trace & trace & trace \\
Androstenedione & trace & trace & trace \\
Testosterone & trace & trace & trace \\
More polar metabolites & 4.4 & 5.5 & 32.7 \\
\hline Metabolites 17 $\alpha$-hydroxylated & 9.7 & 3.5 & 23.3 \\
Product $\Delta^{4}$-3-ketosteroids & 1.0 & 0.2 & 1.0 \\
\hline
\end{tabular}

* Percent yield of the radioactivity to the initially added.

Table 5. Metabolism of $17 \alpha$-hydroxyprogesterone by infantile testes

\begin{tabular}{lcr}
\hline & Y. H. & T. T. \\
\hline 17 $\alpha$-Hydroxyprogesterone (substrate) & $78.7^{*}$ & 49.7 \\
Androstenedione & 0.2 & 0.4 \\
Testosterone & 1.5 & 20.1 \\
Pregn-4-ene-17 $\alpha, 20 \alpha$-diol & 4.3 & 12.6 \\
Product $\mathrm{C}_{19}$-steroids & 1.7 & 20.5 \\
\hline
\end{tabular}

* Percent yield of the radioactivity to the initially added.

conditions were identified on the basis of the derivative formation (oxidation and acetylation) and chromatographic mobilities.

Determination of radioactivity and quantitation of metabolites

Radioactivity of each steroid fraction was measured with a liquid scintillation spectrometer (Type ISC-601, Aloka, Tokyo) in toluene-PPO-POPOP system. The counting efficiency for radiocarbon was approximately $90 \%$. No corrections were made for losses during the analytycal procedures. When radioactive metabolites were recrystallyzed, the yield of each metabolite was corrected by the ratio of constant specific radioactivity measured to the calculated value.

Protein content in the tissue preparation was determined by the method of Lowry et al. (1951).

\section{Chemicals}

4-14C-labeled steroids were purchased from New England Nuclear Corp. (Boston, Mass.) and radiochemical purity was examined by thin-layer chromatography before use. Non-radioactive steroid preparations were obtained from Ikapharm (Ramat-Gan,
Table 4. Metabolism of progesterone by infantile testes

\begin{tabular}{|c|c|c|c|}
\hline & R. G. & Y. H. & T. T. \\
\hline Progesterone (substrate) & $52.3^{*}$ & 58.3 & 20.0 \\
\hline $17 \alpha$-Hydroxyprogesterone & 14.7 & 1.1 & 24.0 \\
\hline Androstenedione & 0.4 & 0.1 & 0.3 \\
\hline Testosterone & 3.4 & 1.3 & 3.6 \\
\hline $20 \alpha$-Dihydroprogesterone & 10.9 & 31.9 & 24.0 \\
\hline \multirow[t]{2}{*}{ Pregn-4-ene-17 $\alpha, 20 \alpha$-diol } & & & 5.2 \\
\hline & $6.8^{* *}$ & $0.3^{* *}$ & \\
\hline $16 \alpha$-Hydroxyprogesterone & & & 10.5 \\
\hline Metabolites $17 \alpha$-hydroxylated & 18.4 & 2.5 & 33.1 \\
\hline
\end{tabular}

Table 6. Metabolism of androatenedione by infantile testes

\begin{tabular}{lrrr}
\hline \hline & R. G. & Y. H. & T. T. \\
\hline Androstenedione (substrate) & $1.3^{*}$ & 1.8 & 1.2 \\
Testosterone & 87.0 & 93.9 & 96.9 \\
\hline * Percent yield of the radioactivity to the initially \\
added.
\end{tabular}

Israel). NAD and NADPH were products of Sigma Chemical Co. (St. Louis, Mo.). All organic solvents were redistilled before use.

\section{Results}

\section{Bioconversion of steroids.}

Percent yields of products to added steroid substrates are tabulated in Tables 3, 4, 5 and 6. Each testis tissue investigated metabolizes steroid substrate in a similar fashion, indicating the presence of significant activities of $17 \alpha$-hydroxylase and C17-20 lyase, markedly high $17 \beta$-hydroxysteroid oxidoreductase activity and trace activity of $\Delta^{5}-3 \beta$-hydroxysteroid dehydrogenase coupled with $\Delta^{5}-\Delta^{4}$ isomerase in these testis tissues. It would be worthy to notice that enzyme activities except C17-20 lyase on the basis of protein or tissue weight were lower in the 

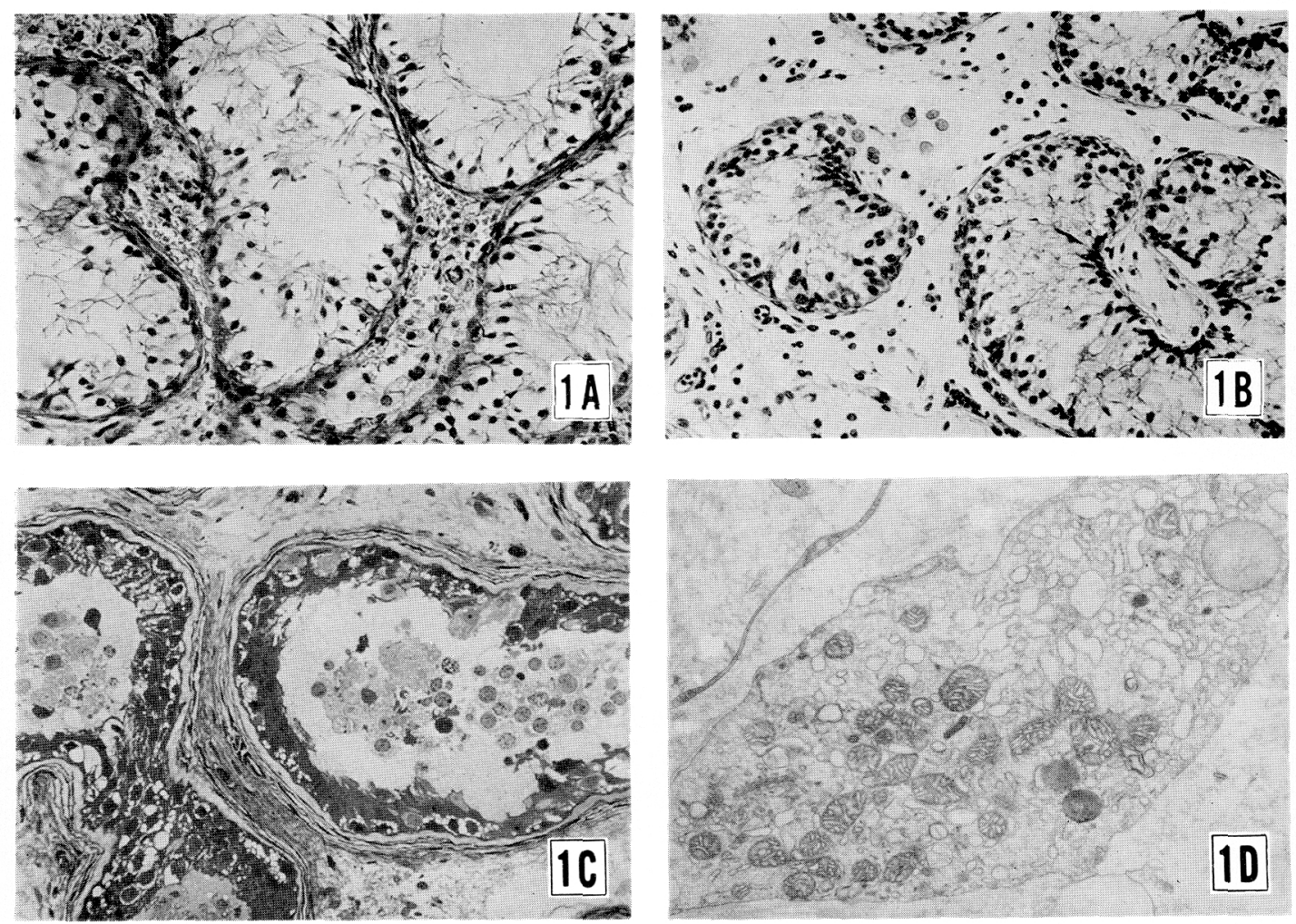

Fig. 1A: Testis obtained from a boy aged 8 months. Seminiferous tubules contain immature Sertoli cells with small ovoid nuclei and elongated slender cytoplasm. Spermatogonia are sparsely distributed. $\times 200$. Fig. 1B: Testis obtained from a boy aged 4 years. Seminiferous tubules reveal almost the same appearance as Fig. 1A. Small fibrocytes and a few lymphoid cells are recognized in intertubular space. $\times 100$. No definite Leydig cells are visible in 1A and 1B. Fig. 1C: Testis obtained from a boy aged 4 years displaying precocious puberty. Seminiferous tubules contain desquamative primary spermatocytes and mature Sertoli cells. There are no Leydig cell nodules. The section is prepared from Epon-embedding material after fixed with glutar-aldehyde-osmium fixative. $\times 200$. Fig. 1D shows a peritubular single cell which resembles to a fibroblast in Fig. 1C. There are numerous mitochondria exhibiting multiple villous cristae and electron-dense matrix, which are specific for Leydig cells. A number of dilated smooth-surfaced endoplasmic reticulum is present. $\times 6000$.

testis tissue of T.T. with precocious puberty than in the testes of the other infants examined, while the testis of T.T. showed the most active steroid metabolism among the three when considered on the basis of a testis. The activity of $\Delta^{5}-3 \beta$-hydroxysteroid dehydrogenase was also low in the tesis of T.T. Although a significant amount of unidentified more polar substances was produced from pregnenolone in this testis, no significant amount of known $\Delta^{4}$-steroids was found in these more polar metabolites and no significant amount of more polar substances was produced from $\Delta^{4}$-steroid substrates.

Histologic findings.

Fig. $1 \mathrm{~A}$ and $1 \mathrm{~B}$ demonstrate the testis tissues of R.G. and Y.H., respectively. Seminiferous tubules are still immature and no apparent Leydig's cell clusters are recognized at intertubular spaces. Fig. 1C and 1D show the testis tissue of T.T. Mature Sertoli's cells and primary spermatocytes are 
recognized in seminiferous tubules but no apparent Leydig cells are present. Under electron microscopy, however, some of fibroblast-like cells at peritubular spaces have mitochondria with villous tubular cristae which characterize the structure of Leydig's cells.

\section{Discussion}

Two of the patients from whom the testis had been removed for the present study were of so-called male pseudohermaphroditism and tne other one was of idiopathic true precocious puberty. Therfore, the testis obtained from the former two might have impaired steroidogenesis, while the testis of the latter one might have enhanced testicular steroidogenesis for his age juding from his manifestation of male secondary sexual characteristics. The histologic observation revealed that the testis of the former two was still immature while the latter one's was initiating spermatognesis. No apparent Leydig's cells, however, were recognized in any testes of them. Consequently, the high activity of $17 \beta$-hydroxysteroid oxidoreductase and the absent or undetectable activity of $\Delta^{4}$-steroid $5 \alpha$-reductase observed in all testis tissues examined do not appear due to impaired testicular functions, but appear the biological properties of testicular steroidogenesis of the human before or at puberty. The significant activity of $17 \beta$-hydroxysteroid oxidoreductase was also observed in the testis tissue of a 14-year-old boy when testosterone was incubated as a substrate, but the oxidase function of the oxidoreductase and $5 \alpha$-reductase activity were limited in tubules and Leydig's cells separated from the testes of boys under 4 years (Rivarola et al., 1973). Mizutani et al. (1977) found the limited activity of $5 \alpha$-reductase in immature human testes. Richards and Neville (1973), however, found $5 \alpha$-reductase active and $17 \beta$-hydroxysteroid oxidoreductase activity limited in the testis tissue adjacent to an interstitial cell tumor of a 4-year-old boy. In rat testes, $5 \alpha$-reductase and $17 \beta$-hydroxysteroid oxidoreductase become active respectively at the initial and at the late stage of sexual maturation (Inano et al., 1967), and the oxidoreductase activity is not enhanced by $\mathrm{hCG}$ administration after 21 days old (Oshima et al., 1970).

The present study demonstrates the presence of enzyme activities related to biosynthesis of testosterone from pregnenolone in immature human testes, although the activity of $\Delta^{5}-3 \beta$-hydroxysteroid dehydrogenase is very limited. The similar result has already been reported previously (Mizutani et al., 1977). These findings support the presence of testicular androgens in peripheral blood of infants and children (Forest et al., 1976). These enzyme activities per testis except $\Delta^{5}-3 \beta$-hydroxysteroid dehydrogenase increase in the testis of a boy with true precocious puberty, being consistent with the initiation of his sexual maturation. The result suggests that the induction of $\Delta^{5}-3 \beta$-hydroxysteroid dehydrogenase might occur at the adanced stage of puberty in the human testis. The dehydrogenase activity is histochemically recognized in human testes of new born children under 2 days, pubertal boys over 16-year-old boy receiving hCG administration, but not recognized in testes of boys aged from 5 days to 6 years (Sengoku, 1967). A significant formation in vitro of $\Delta^{4}$-steroids from pregnenolone has been reported in the testis tissue adjacent to virilizing interstitial cell tumor of a 7-year-old boy (Mizutani et $o l ., 1977)$. In contrast, $\Delta^{5}-3 \beta$-hydroxysteroid dehydrogenase is markedly enhanced at the beginning of sexual maturation in the rat testis (Inano et al., 1967; Shikita and Hall, 1967).

The enzym activity related to the testosterone formation from pregnenolone in immature human testes can be considered to be localized in immature Leydig's cells which are distinguishable from fibroblasts. 
under electron microscopy (Hatakeyama and Oshima, 1967), since the amount of metabolites produced by the enzymes on the basis of either tissue weight or protein is low in the testis where other cell components than Leydig's cells are increasing.

Although human testes utilized for the present study may not be biologically normal, the following would be concluded: (1) Active $17 \beta$-hydroxysteroid oxidoreductase is present in immature human testes when NADPH is added. (2) $5 \alpha$-Reductase activity is very limited in a testis initiating spermatogenesis. And (3) activation of $17 \alpha$ hydroxylase and $\mathrm{C} 17-20$ lyase proceeds to the induction of $\Delta^{5}-3 \beta$-hydroxysteroid dehydrogenase at the initiation of testiclar function of the human.

\section{Acknowledgement}

The present work was partly supported by a Grant-in-Aid, No. 234047, from the Ministry of Education, Science and Culture, Japan.

\section{References}

Forest, M. G., E. DePeretti and J. Bertland (1976). Clin. Endocrinol. 5, 531.

Hatakeyama, S. and H. Oshima (1976). Gumma Symp. Endocrinol. 13, 81.

Inano, H., Y. Hori and B. Tamaoki (1967). Ciba Found. Colloq. Endocrinol. 16, 105.

Lowry, O. H., N. J. Rosen brough, A. L. Farr and R. T. Randall (1951). J. Biol. Chem. 193, 265.

Mizutani, S., T. Tsujimura, S. Akashi and K. Matsumoto (1977). J. Clin. Endocrinol. Metab. 44, 1023.

Oshima, H. (1971). J. Japan Med. Assoc. 65, 271. (In Japanese)

Oshima, H., T. Sarada, K. Ochiai and B. Tamaoki (1970). Endocrinology 86, 1215.

Oshima, H., T. Sarada, K. Ochiai and B. Tamaoki (1974). Inv. Urol. 12, 43.

Payne, A. H. and R. B. Jaffe (1975). J. Clin. Endocrinol. Metab. 40, 102.

Richards, G. and A. M. Neville (1973). J. Endocrinol. $59,637$.

Rivarola, M. A., E. J. Podesta, H. E. Chemes and D. Aquilar (1973). J. Clin. Endocrinol. Metab. 37, 454.

Sengoku, K. (1967). Bull. Tokyo Med. Dent. Univ. 14, 51 .

Shikita, M. and P. F. Hall (1967). Biochim. Biophys. Acta 136, 484.

Steelman, S. L. and R. M. Pohley (1954). Endocrinology 53, 604.

Tanner, J. M. Growth at Adolescence, 2nd ed. Blackwell Scientific Publication, Oxford and Edinburgh, p. 28 (1962).

Yokota, N., M. Igarashi and S. Matsumoto (1965). Endocrinol. Japon. 12, 83. 